\title{
Promoting Child Survival in Rural Districts in East Malaysia
}

\author{
Chong-Ying Gan \\ Department of Social and Preventive Medicine, University of Malaya, Malaya, Malaysia
}

\begin{abstract}
In developing countries, local health authorities do improve health care delivery system based on the results from the studies conducted by the Institutes and Universities. This paper is to introduce an example of such project in East Malaysia. Project to promote child survival has been carrying out for one rural district in Sabah, East Malaysia. The phase I study is collection of baseline data or situational analysis, Phase II is intervention program (health education) and Phase III is evaluation of the intervention program. In Phase I study, five categories of variable for determinants of child survival were socioeconomic determinants, maternal factors, environmental factors, nutritional factors and health service utilization factors. Based on the findings from Phase I study, a number of intervention programs are now being implemented.
\end{abstract}

Child survival, Rural area, Situational analysis, Health education, Evaluation

\section{INTRODUCTION}

In developing countries, nationwide health care planning will offer almost all areas a certain basic level of services and facilities but will seldom identify the particular needs of smaller areas or communities. Budget constraints in developing countries do not permit situational analysis for every particular geographical location or epidemiological situation. Apart from this, local health departments are invariably fully occupied with service delivery and have little time for research. The purpose of this article is to advocate that research institutions and universities play a role in the situational analysis of the smaller communities. By doing so, local health authorities can then improve their health care delivery systems. This article proceeds to describe an example of such a project already in progress in East Malaysia.

\section{PROJECT AREA}

Geographically, Malaysia can be described as being made up of West (Peninsular) Malaysia and East Malaysia which is located on the island of Borneo. Two out of the 14 States 
(inclusive of Federal Territory) in Malaysia are in East Malaysia and they are namely Sabah and Sarawak. In general, West Malaysia is more developed than East Malaysia. East Malaysia has large areas of jungle, difficult terrain and a diversity of ethnic groups living in remote areas. Most of the districts in East Malaysia can be considered as rural. The health indices of East Malaysia are not favourable when compared to those of West Malaysia.

Like most developing countries, health care services are planned on a nationwide scale. Although there is an existing infra-structure for the delivery of health services in East Malaysia, it is felt that for the smaller communities a more detailed situational analysis followed by appropriate intervention programmes would give an impetus to better health. It is for this reason that a pilot project to promote child survival was carried out for one rural district in Sabah. The project is located in a rural district called Tambunan. It has a population of about 22,000 (1984 census) and more than $90 \%$ of the people are Kadazans. Ninety-five percent of those working are farmers and more than $90 \%$ of the population are Catholics. The health services in the district include one district hospital (manned by one doctor during the study period in 1988), one health centre, one rural dispensary and 5 clinics run by rural health nurses. The doctor: population ratio for the district was thus $1: 22,000$ during the first phase of the project.

\section{PROJECT PHASES}

The project to promote child survival in this district has 3 phases:

Phase I: Collection of baseline data for situational analysis

Phase II: Intervention programme (Health Education)

Phase III: Evaluation of the intervention programme

The first phase of the project involved the collection of baseline data on the determinants of child survival for situational analysis. A survey which involved the interview of mothers using a semi-structured questionnaire, anthropometrical measurements of children, and the checking of immunization cards and birth certificates was carried out. The sampling unit was households with children below 6 years of age. A two stage sampling procedure was used to select the study sample. The first stage involved the purposive selection of 4 clusters of villages. The second stage involved random sampling of 23 villages from these 4 clusters. Every household in each village selected which had children below 6 years were included in the survey. This yielded 418 households. (Data collection was carried out in 1988).

Five categories of variables which constitute the determinants of child survival ${ }^{(1)}$ were collected.

- Socioeconomic determinants

e.g. - income

- transport facilities

- educational level

- occupation

- Maternal factors

e.g. - birth weights

- pregnancy histories

- birth intervals

- family planning practices

- practices during pregnancy 
- Environmental factors

$$
\begin{aligned}
& \text { e.g. - water supply } \\
& \text { - excreta disposal } \\
& \text { - housing }
\end{aligned}
$$

- Nutritional factors

$$
\begin{aligned}
& \text { e.g. - dietary pattern of children } \\
& \text { - anthropometry }
\end{aligned}
$$

- Health service utilization factors (Personal illness control, personal preventive measures)

$$
\begin{aligned}
\text { e.g. - antenatal care } \\
\text { - immunization coverage } \\
\text { - type of birth attendants } \\
\text { - place of delivery }
\end{aligned}
$$

\section{RESULTS OF PHASE I}

Phase I of the project has been completed and the main problems detected are outlined as follows:

1) Difficulties in getting transport to attend health clinics/centres is a major set-back to the utilization of health services.

2) Large families and short inter-pregnancy intervals.

3) Toddler nutrition not satisfactory

4) Antenatal care visits, trained birth attendants utilization, immunization coverage can be further improved.

5) Diseases related to poor sanitation remain a problem.

\section{IMPLICATIONS OF PROJECT}

As a result of the findings in Phase $I$, a number of intervention programmes are now being implemented. (The project is currently in Phase II). The family planning programme is being strengthened in the district by the State Maternal and Child Health Services. Health education materials to suit local needs are being prepared by the investigators and the health education programme will soon be implemented.

Upon the completion of Phase II, an evaluation of the intervention programmes will be carried out. This assessment constitutes Phase III of the project and will determine whether the intervention programmes have been successful or not.

This particular project is a collaborative effort between the university and the local health department. It is an example of how research institutions and health departments can work together to promote health in areas which need that extra impetus. As health departments in most developing countries are invariably fully occupied with the delivery of health services, it is advocated that research institutions and universities generate useful information for them to utilize. It is hoped that other deserving districts in East Malaysia will also have similar type projects to promote child survival. 


\section{ACKNOWLEDGEMENT}

The pilot project "Promoting Child Survival in a Rural District in Sabah, Easy Malaysia" is supported by a grant from the Asia Pacific Academic Consortium of Public Health. The author wishes to thank the Director of Medical Services, Sabah and the District Officer of Tambunan for their co-operation in the pilot project.

\section{REFERENCE}

1. Mosley, W.H., Chen, L.C.: Child survival - Strategies for research. In Population and Development Review (Suppl.), Vol 10, 1984. 